\title{
A identidade nacional: inseparável da própria percepção coletiva, mas mutável consoante os grupos humanos e a época
}

\author{
MATTOSO, José. A identidade Nacional. Lisboa: Gradiva \\ Publicações, 1998. 114p. Coleção da Fundação Mário Soares. \\ ISBN: 978-9726626046.
}

\section{Marco Pais Neves dos Santos*}

José Mattoso aborda a problemática da identidade nacional, e procura demonstrar o desenvolvimento da consciência de pertença a um coletivo nacional, particularizando o caso português. Antes de mais, refere que uma nação é uma determinada população humana, que partilha um território histórico, mitos e memórias comuns, uma economia comum, uma cultura de massas comum, politicamente é soberana, e possuí um conjunto de códigos legais que regulam a ação de todos os membros. ${ }^{1}$

José Mattoso começa por definir identidade nacional como o resultado da noção que os cidadãos possuem de constituírem uma coletividade humana, mutável consoante os grupos humanos e a época. Refere que a melhor forma de abordar esta questão é considerar que, as condições para a compreender, são as mesmas de qualquer outro objeto, seja ele individual ou coletivo. Paralelamente, esboçou alguns temas que serão tratados de forma mais aprofundada e apresentou a organização da obra, dividindo-a em duas partes: a primeira parte consiste nos capítulos 1-3 e a segunda parte nos capítulos 4-8. Esta será também a divisão a ter em conta nesta análise, para que o resultado seja um comentário crítico, lógico e coerente.

A primeira divisão consiste na percepção das diferentes etapas da manifestação da identidade nacional, desde a fundação do Estado até à atualidade. Deste modo, o primeiro capítulo, denominado "O processo de categorização da identidade nacional", refere que a consciência de pertença a um país se pode refletir na expressão: "nós somos portugueses; os outros são

1 MATTOSO, José. A identidade Nacional. Lisboa: Gradiva Publicações, 1998. O mesmo enquadramento, quanto à determinação da nação, é apresentado por SMITH, Anthony. Identidade Nacional. Lisboa: Gradiva Publicações, 1997 [1991].

* Doutorando em Desenvolvimento Social e Sustentabilidade pela Universidade Aberta de Portugal. Técnico Superior no Instituto da Construção Civil e do Imobiliário (InCI).E-mail: marco.santos@inci.pt 
estrangeiros", ${ }^{2}$ embora este facto outrora não fosse evidente para todos os sectores sociais.

Estabelecendo uma relação com Orvar Löfgren, ${ }^{3}$ e partindo do princípio que o culto dos sentimentos de pertença nacional no seio de um determinado país é da máxima importância nos modos de construção da nação, a comunicação externa ocupa também aí um lugar decisivo. Entende-se, nesse sentido, que a prova de uma identidade nacional é inócua se restringida às próprias fronteiras e que uma nação só se consegue afirmar, se for aceite enquanto tal pelas restantes comunidades internacionais. É a necessidade de tal reconhecimento que explica, por sua vez, a relevância de eventos como as exposições universais, para a afirmação da nação. ${ }^{4}$

De acordo com José Mattoso, ${ }^{5}$ foi lentamente que "os nacionais" se foram consciencializando da sua pertença à categoria dos portugueses através de fenómenos históricos, normalmente, confrontações militares com estrangeiros ou civilizações distantes, explicados cronológica e pormenorizadamente pelo autor. Tal como refere Tilly, "a guerra faz o Estado e o Estado faz a guerra" ${ }^{6}$ Contudo, este refere que a generalização da noção de identidade nacional só se deu após o desenvolvimento da escrita, da imprensa e da participação dos indivíduos na vida política. Neste seguimento, não parece de todo correto extrapolar este conceito para toda a população no estudo de um período ancestral, por oposição ao que ocorre na atualidade.

O capítulo "Atribuição de significado" procura constituir um conjunto de noções que atribuem sentido à identidade nacional. Para tal foram tidos em conta e explicitados os seguintes conceitos: reino, naturalidade, pátria, fronteira, sucessão régia e o poder sagrado do rei. A seleção destes últimos prende-se com o facto de se terem constituído na Idade Média e influenciado de forma significativa o fortalecimento da consciência da identidade nacional.

É de ressaltar a associação destes conceitos ao poder político, tido como o mais relevante para a formação da identidade nacional.

Os itens enunciados anteriormente foram influenciando lentamente a população: inicialmente, apenas os mais próximos da corte, do poder ad-

\footnotetext{
2 MATTOSO, op. cit, p.13.

3 LÖFGREN, Orvar. The Great Christmas Quarrel and Other Swedish Traditions. MILLER, D. (ed.), Unwrapping Christmas. Oxford: Clarendon Press, 1993, p. 217-234.

4 Ibidem.

5 MATTOSO, op. cit.

6 TILLY, Charles. The formation of National States in Western Europe. United States: Princeton, University Press, 1975, p. 42.
} 
ministrativo e clérigos; sendo que, possivelmente, os restantes habitantes foram mais influenciados pelo uso "símbolos de referência colectiva", tais como: "o escudo de armas do rei, a bandeira nacional e a moeda".

Em concordância com Mattoso ${ }^{9}$ está Löfgren, ${ }^{10}$ que definiu o nacionalismo num período mais contemporâneo como um gigantesco "Do it Yourself Kit" (faça você mesmo), acrescentando que as ideias circulam primeiramente pelas elites intelectuais e resultam numa espécie de "check list", fundamentada em: todas as nações têm que ter uma linguagem comum, um passado e destino comum, uma cultura popular, valores de nacionalismo de mentalidade e carácter, galeria de mitos e heróis nacionais e respetivos vilões, e um conjunto de símbolos que incluem bandeiras, brasão, textos e imagens sagradas.

No último capítulo (do conjunto a que inicialmente designámos de primeira parte), denominado "Atribuição de valor", o autor afirma que o "valor" concedido à identidade nacional é superior caso se procure defendê-la em virtude do benefício dos sujeitos que nela interferem, podendo mesmo tornar-se supremo, quando tidos em consideração os interesses da coletividade.

Estas noções são indissociáveis do conceito de "pátria", problemática desenvolvida neste capítulo, que apresenta a sua evolução ao longo do tempo, até atingir a sua expressão atual. $O$ autor salienta ainda que a atribuição de valor à identidade nacional foi um fenómeno lento, procurando reconstituir alguns pontos da sua formação com base em testemunhos históricos. Em suma, a análise da identidade nacional por meio de uma visão histórica é indissociável da noção coletiva. Deu-se um longo caminho na formação da consciência de pertença a um coletivo nacional, partindo de um fator político (apropriação do poder por um chefe com autoridade própria sobre os vassalos), que se expandiu para sectores não só do mesmo domínio, mas também sociológicos e psicológicos.

A segunda delimitação da obra, de uma forma geral, baseia-se na análise profunda dos elementos que caracterizam a identidade nacional, através do estudo de caracteres: geográficos, políticos, sociológicos e comportamentais.

7 MATTOSO, op. cit., p. 15.

8 Ibidem, p. 28.

9 Ibidem.

10 LÖFGREN, op. cit. 
Do ponto de vista geográfico e como referido por A. H. de Oliveira Marques, "não faz hoje sentido falar de uma unidade do território português (...) ou de uma individualidade geográfica de Portugal dentro do conjunto da Península Ibérica" ${ }^{11}$ Efetivamente a identidade geográfica de base física é muito ténue, uma vez que a originalidade morfológica é praticamente insignificante.

Portugal localiza-se no extremo sudoeste da Península Ibérica partilhando da morfologia da mesma, relativamente ao resto do continente europeu, formando deste modo, uma unidade geográfica bem individualizada. Assim, Portugal integra-se na morfologia peninsular, integração tanto mais evidente quanto é certo que, como mostra qualquer mapa físico, as grandes linhas de relevo de Portugal não são mais do que a continuação das linhas de relevo de Espanha, as superfícies planálticas constituem a bordadura ocidental dos grandes planaltos ibéricos e os grandes rios que desaguam na nossa costa têm a maior parte do seu percurso em território espanhol. Deste modo, é de todo pertinente afirmar que o País foi uma construção dos homens e não da natureza.

Todavia, e apesar de Portugal apresentar uma certa homogeneidade em termos físicos, como constata, e bem, o autor, é possível observar contrastes regionais, não só entre as áreas a norte e a sul, mas também entre as do litoral e as do interior. Assim, importa individualizar as condições geográficas, que muito embora não sendo suficientes para conferir ou não identidade nacional, acabam por influenciar, dar suporte e impulsionar as transformações socioeconómicas, que moldaram a evolução regional do País, uma vez que em conjunto determinam o grau de atração ou repulsão que a terra exerce sobre as comunidades humanas, evidenciando certas especificidades regionais.

Observando as diferentes regiões de Portugal Continental em termos de relevo, verifica-se que o Minho interior apresenta relevos acentuados com topos aplanados entre os $1300 \mathrm{~m}$ e os $1600 \mathrm{~m}$. É o caso das serras da Peneda, Gerês, Soajo e Amarela, cortados pelos rios Minho, Lima, Cávado, Homem e Ave. O Minho litoral é mais plano, cortado por rios que se espraiam em planícies aluviais largas para em seguida desaguarem no oceano. Trás-os-Montes apresenta áreas planálticas separadas por vales e depressões. As serras mais importantes são a de Alvão e Padrela, sendo entre elas que corre o rio Corgo. O rio Douro constitui como que uma fronteira para as Beiras.

11 MARQUES, A. H. de Oliveira. História de Portugal. Das Origens ao Renascimento. Vol. I. Lisboa: Editora Presença, 1997, p. 17. 
O relevo das Beiras é influenciado pelos diversos deslocamentos tectónicos e entre eles encontramos a cordilheira central, que separa a Meseta norte da Meseta sul. Esta superfície vai-se prolongando pelo sul, onde se encontram as serras de S. Mamede, Marvão e Ossa, estabelecendo-se a separação com o Baixo Alentejo. No Algarve encontram-se as serras de Monchique, Caldeirão e Espinhaço de Cão. De facto, cerca de $60 \%$ das terras baixas, ou seja, com menos de $200 \mathrm{~m}$ de altitude, situam-se a sul do Tejo. Em contrapartida, cerca de $95 \%$ das terras altas localizam-se a norte do rio Tejo. ${ }^{12}$

Tal como o relevo, também o clima de Portugal é marcado pelo contraste entre o norte e o sul, e o litoral e o interior, divisões afloradas e aceites pelo autor, ainda que com base noutros autores. Assim, o norte caracteriza-se pela ocorrência de invernos frios e chuvosos, com queda de neve, durando o período chuvoso e nebuloso cerca de seis meses. O sul apresenta temperaturas mais elevadas ao longo de todo o ano. o período chuvoso e nebuloso é mais curto do que a norte, durando cerca de três meses.

Sendo Portugal, como refere o autor, um país cuja atividade económica predominante foi sempre, até há pouco tempo, a agricultura, facilmente se depreende que as condições naturais não favorecem esta prática, já que um dos maiores problemas para o desenvolvimento das espécies vegetais é a irregularidade da precipitação. Outro aspeto de grande importância é o relevo, uma vez que a altitude é um fator que condiciona a agricultura. Os declives acentuados das encostas contribuem para uma maior erosão dos solos, fazendo com que os detritos minerais e vegetais, que os compõem, sejam arrastados pelas vertentes e levando a que os solos se apresentem pouco espessos e pobres em húmus. Outro fator muito importante é a natureza do solo arável. Pois o clima mediterrâneo não permite a formação de solos profundos. Os baixos totais pluviométricos e a distribuição irregular da precipitação ao longo do ano, coincidindo a estação mais seca com a de temperaturas mais elevadas, não favorecem a alteração química da rocha-mãe. Por isso, uma das regiões que reúne melhores condições naturais, e que por isso sempre atraiu os cultivadores, é o norte litoral, mais concretamente o Minho, como refere o autor. Todavia, como já ficou demonstrado a favor da tese do autor, a proporção de terras com pouco rendimento é muito superior às terras com grande rendimento. Assim, verificaram-se, na história portuguesa, várias tentativas para aproveitar melhor os recursos agrícolas, nomeadamente por desbravamento de terras desocupadas, aproveitamento

12 RIBEIRO, Orlando. Portugal, o Mediterrâneo e o Atlântico. Lisboa: Livraria Sá da Costa Editora, 1998. 
de solos incultos e secagem de terrenos pantanosos, nos séculos XI, XII e XIII respetivamente, como menciona o autor. No entanto, a crise demográfica e a crise económica dos séculos XIV e XV promoveram o abandono de muitos terrenos pouco produtivos.

Assim, o clima, o relevo, a fertilidade dos solos ou os recursos hídricos são alguns exemplos de fatores naturais que condicionam a distribuição espacial da população portuguesa, uma vez que era nos locais que reuniam melhores condições que as pessoas se fixavam, para além da fixação em pontos elevados por motivos defensivos e na região fronteiriça, nomeadamente entre Castelo de Vide e Serpa.

Por outro lado, os fatores humanos ganharam importância, e a existência de recursos naturais, a acessibilidade e o desenvolvimento industrial deram origem à concentração de um elevado número de centros urbanos na faixa litoral, exceto ao longo da costa alentejana, sendo responsáveis pela desigual distribuição espacial da população no nosso país.

Na segunda metade do século XX, verificou-se uma nova dinâmica: a suburbanização, originando o crescimento de novos centros urbanos. Este processo gera um conjunto de problemas nas áreas metropolitanas, cujas estruturas não estão preparadas para tanta população, entrando em rutura. Por outro lado, contribuem para o despovoamento do interior do país. A última década tem, no entanto, evidenciado uma nova dinâmica na concentração populacional, resultante do desenvolvimento da rede rodoviária no interior do País, do dinamismo económico de certas regiões, e da fixação de jovens pela existência de Universidades e Politécnicos, nomeadamente nas capitais de distrito, o que de acordo com o autor vem confirmar a influência das funções administrativas, mas que, na verdade, os fatores justificativos são bem mais abrangentes, como já se evidenciou.

Assim, aglomerações urbanas como Castelo Branco, Viseu, Covilhã ou Évora conheceram um dinamismo muito significativo, contrariando a tendência de perda populacional que se mantinha há alguns anos.

O capítulo "O factor político" coloca o político como o elemento em análise mais importante na construção da identidade nacional. José Mattoso vai explicitar as repercussões do poder político, analisando o próprio nome de "Portugal". Deste modo, problematiza o porquê da extensão do nome "Porto" a todo o país, refere a importância deste centro urbano em épocas ancestrais, e apresenta acontecimentos históricos, percorrendo superficialmente um hiato temporal que vai desde a ocupação dos povos bárbaros até ao conde D. Henrique. Salienta que a origem de Portugal reside em factos 
político-administrativos e não na etnia, e que o Estado português nunca procurou fazer prevalecer nenhuma etnia ancestral, sobrepondo-se "a elas como uma entidade política"13. Aborda teorias de outros autores que procuraram as origens nacionais em povos cujos atuais principais representantes são os minhotos, beirões ou alentejanos, o que contraria a ideia que formulou no trabalho, e por isso refere que essas teorizações são consideradas pouco credíveis, uma vez que este é um fenómeno do domínio administrativo, político e estatal, e não do plano cultural ou étnico.

No sexto capítulo "O poder político e as regiões" o autor indica que as teorias referidas no parágrafo anterior, relacionadas com os nomes que designam as províncias nacionais, permitem constatar a vertente política da construção portuguesa. Considerando que as designações não estão associadas a antepassados étnicos, pressupõe-se a existência de uma administração central. $\mathrm{O}$ autor explora ainda os contrastes das diversas regiões do território nacional e retoma as duas dicotomias (norte-sul e litoral-interior), remetendo para exemplos históricos e concretos que materializam as afirmações que enuncia. Em suma, "o que cria e sustenta a identidade nacional é, de facto, o Estado", ${ }^{14}$ justificando o lento desenvolvimento da consciência nacional e a sua manifestação tardia em termos populares.

O capítulo "Configuração do poder político e a sua relação com as forças sociais", procura associar, tal como o próprio título indica, o poder político ao domínio social. Esta temática é, principalmente, desenvolvida segundo as tentativas de determinados reis portugueses consolidarem o seu poder, pelo que o autor apresenta as medidas políticas tomadas, que permitiram o desenvolvimento de instrumentos de centralização da monarquia. Mais tarde, a superioridade do Estado continuou a aumentar e os poderes públicos e administrativos foram, progressivamente, passando para o monopólio do Estado. José Mattoso explora a situação de diversos estratos sociais, tais como: os que usufruem de regalias régias e estão associados à corte (nobreza e clero), os camponeses, a burguesia mercantil e citadina e os fidalgos.

No capítulo final da obra "Identidade Sociológica", o autor refere, citando uma afirmação de Boaventura Sousa Santos, que: "o excesso mítico de interpretação [do processo da identidade nacional] é um mecanismo de compensação do défice da realidade", ${ }^{15}$ criando na mente dos autores, características ilusórias dos nacionais.

13 MATTOSO, op. cit, p. 67.

14 Ibidem, p. 83.

15 Ibidem, p. 98. 
Estabelecendo um paralelo com Benedict Anderson, ${ }^{16}$ pode complementar-se a informação incontestável de José Mattoso. ${ }^{17}$ Anderson, no seu trabalho, definiu a nação como uma comunidade política imaginada; imaginada inerentemente quer como limitada quer soberana. Isto porquê? De facto, nem os membros da mais pequena nação se conhecem todos, mesmo que na mente de cada um deles viva a imagem da sua comunhão, o que significa que todas as comunidades são imaginadas e que a distinção se faz pela forma como são imaginadas; a forma que cada indivíduo utiliza para interpretar e idealizar a sua comunidade e constituir um sentimento nacional. Igualmente, é limitada (a nação tem fronteiras físicas que a delimitam de outras nações), e é soberana, apesar de este termo somente ter surgido a partir das luzes e da revolução de 1789, porque foi destruída a legitimidade da ordem divina, do domínio dinástico hierárquico. Contudo, é percetível que o ponto fulcral do último capítulo de Mattoso ${ }^{18}$ reside na imutabilidade da identidade nacional dos portugueses, por comparação à constante modificação dos caracteres sociais. Revela-se necessária a existência de uma consciência coletiva, baseada numa compreensão das diferenças nacionais relativamente aos "estrangeiros" e na percepção da existência de um passado comum. Deste modo, a História revela um dos elementos mais importantes na consolidação da memória coletiva e, consequentemente, da consciência de identidade, fortalecendo também sentimentos patrióticos.

Para finalizar, fazendo uma apreciação metodológica sumária, importa referir que: (1) a obra foi organizada de forma hierarquizada desde a introdução até ao último capítulo, e toda a massa argumentativa está bem inserida dentro de cada capítulo; (2) a forma como o autor se expressou é relevante em termos científicos, mas não tanto em termos pedagógicos, uma vez que a informação não deve estar somente acessível à comunidade científica, a quem é claramente destinado este trabalho, mas também à população em geral. Assim, julga-se que será um importante argumento para motivar uma ligeira alteração textual a ter lugar numa próxima reedição.

No âmbito da análise do conteúdo, tal como referido anteriormente, esta obra pretende explicar a evolução da consciência de identidade nacional, nos seus vários domínios. Para tal, José Mattoso recorre, sistematicamente, a referências históricas que ilustram as teorias por ele apresentadas

16 ANDERSON, Benedict. Imagined communities. Reflections on the Origin and Spread of Nationalism. New York: Editora Gopal Balakrishnan, 1991 [1983].

17 MATTOSO, op. cit.

18 MATTOSO, op. cit. 
e, paralelamente, apresenta opiniões e citações de muitos outros autores, por vezes, problematizando-as.

A consciência de pertença a uma coletividade nacional em períodos ancestrais era muito menos abrangente, comparativamente à atualidade. Contudo, tal não significa que não existam antecedentes históricos da consciência nacional. Este foi um processo que se desenvolveu de forma gradual, impulsionado por determinados acontecimentos históricos.

Tal como José Mattoso procurou demonstrar nesta obra, estes fenómenos de carácter histórico encontram-se, maioritariamente, associados a uma coletividade humana unificada e sujeita a um mesmo poder político soberano, embora influenciando, principalmente, por aqueles que estão associados ao poder central. No entanto, a realidade é que são estas minorias "que contam a história e a transformam em epopeia colectivas". ${ }^{19}$ Concretiza que o poder político é crucial na construção da identidade nacional. A origem de Portugal e, com ele da consciência de pertença a um país, consiste em fenómenos político-administrativos. Só posteriormente este conceito se difunde a outros domínios, atingindo a sua plenitude atual.

São várias as questões em aberto ao longo do texto. Primeiramente, o autor indica que os linguistas têm um longo caminho a percorrer, de forma a documentarem de forma precisa as diversidades dialetais e as suas expressões históricas. ${ }^{20}$ Outra questão que se encontra em aberto, e que certamente levará à escrita de várias monografias não só por sociólogos, mas por todas as ciências sociais (sociólogos, psicólogos, filósofos, antropólogos, entre outros), é a evidente mutação do sentimento da identidade nacional, por força de um sentimento de exclusão - quebra de receitas financeiras, levando à desagregação dos grupos sociais e inerentemente à adoção de outros valores identitários. Esta questão que o autor colocou é muito pertinente e deve ser complementada em relação às novas dinâmicas culturais, que surgem enraizadas no fenómeno da globalização, e que, efetivamente, também estão ligadas com a questão anterior, forçando a seguinte questão: tendo por base que o sentimento de pertença a um coletivo é feito com base num conjunto de valores, ${ }^{21}$ a atual "mentalidade" mundial baseada no processo da globaliza-

19 MATTOSO, José (dir.). História de Portugal, Vol. I - Antes de Portugal. Lisboa: Círculo de Leitora, 1992, p. 15.

20 MATTOSO, José. A identidade Nacional. Lisboa: Gradiva Publicações, 1998.

21 LÖFGREN, Orvar. The Nationalization of Culture. In: Ethnologia Europaea, N. XIX, p. 5-24, 1989; ANDERSON, op.cit.; SMITH, Anthony. Identidade Nacional. Lisboa: Gradiva Publicações, 1997 [1991]; MATTOSO, José. A identidade Nacional. Lisboa: Gradiva Publicações, 1998. 
ção, será favorável a esta manutenção? Será que os valores que caracterizam a identidade nacional, sobretudo aqueles mais ligados às questões culturais, como a língua e costumes, permaneceram inalterados ao longo tempo? Ou será que podem desaparecer levando consigo o sentimento nacionalista?

É também uma questão pertinente na análise política da atualidade, para a concretização do sonho europeu, que não poderíamos deixar de referir: a identidade supranacional que decorre do federalismo. Numa situação de federalismo, questão que há muito tempo excita os políticos europeus, ${ }^{22}$ será possível a salvaguarda do valor intrínseco da diversidade cultural e política? ${ }^{23}$ Será que os portugueses vão identificar-se como cidadãos europeus, em primeiro, e como cidadãos portugueses, em segundo? Ou seja, vão primeiro apelar à sua identidade supranacional, e só depois à sua identidade nacional (é que sem a emergência de um povo europeu não haverá estado federal europeu)? ${ }^{24}$ Será que a mutação para uma identidade supranacional, a efetivar-se, é o resultado da salvaguarda da diversidade cultural e política dos países membros? Lembra-nos, desde logo, o efeito que esta decisão pode produzir nos doze países europeus com monarquias, com símbolos de referência coletiva, por extensão da ideia de José Mattoso (ex. o escudo de armas do rei), ${ }^{25}$ e com uma linguagem e um passado comum, valores de nacionalismo de mentalidade e carácter, galeria de mitos e heróis, e um conjunto de símbolos que incluem brasão, textos e imagens sagradas, por extensão do pensamento de Orvar Löfgren. ${ }^{26} \mathrm{O}$ federalismo é um modelo governativo que, a bem da identidade nacional e da vontade individual, deve representar o último recurso da salvação do projeto europeu. A sua materialização só deve ocorrer após referendada a população de todos os Estados membros, com aprovação mínima da maioria de cada um dos Estados (e da maioria dentro das minorias), e a sua manutenção deverá depender de objetivos, segundo o princípio de Dusan Sidjanski, "garantindo o desenvolvimento das

22 SIDJANSKI, Dusan. Para um Federalismo Europeu - Uma perspetiva inédita sobre a União Europeia. Cascais: Principia, Publicações Universitárias e Cientificas, 2001, p. 7.

23 Como é natural, no debate do federalismo há que ter em conta as questões latentes da equidade na retribuição e redistribuição de recursos entre os Estados membros, e nos esforços orçamentais, salvaguardando a não germanização da Europa. Portanto, assuntos muito importantes, mas que não são centrais a este ensaio.

24 De alguma forma, os europeus já se vêm a si próprios enquanto europeus, o que resulta, desde logo, da Europa ser uma criação com vista à harmonia política, num continente com uma longa história de guerras entre os Estados.

25 MATTOSO, José, A identidade Nacional, p. 15; 28.

26 LÖFGREN, op. cit. 
riquezas culturais e das identidades nacionais e regionais num conjunto susceptível de criar uma comunidade de destino e unir os Europeus numa grande aventura ao serviço do homem". ${ }^{27}$ Serão estas as questões a ter em conta num futuro próximo e que certamente irão dinamizar a questão da identidade nacional.

Todavia, nesta matéria existem algumas respostas. Segundo Inda e Rosaldo, ${ }^{28}$ o que se verifica atualmente é a desterritorialização da cultura, ou seja, a globalização transportou os elementos culturais para fora do limite territorial da nação, provocando uma alteração profunda desses valores culturais, bem como o significado do que para os cidadãos de um determinado lugar é a identidade nacional. Isto explica-se por uma constante absorção e reinterpretação de valores em todo o mundo, resultando numa reteritorialização final, que no fundo é um composto de várias culturas que se traduzem em formas diferentes de abordar as questões de identidade nacional, apesar de estas não se extinguirem nem se alterarem na totalidade, somente são alvo de uma mutação.

Tal como José Mattoso afirmou em outra obra, por si coordenada e dirigida, "o fenómeno da consciência nacional é um problema importante da história de um país e tem de ser estudado também como um fenómeno que se desenvolve através de um processo lento e complexo, de cuja interpretação é necessário excluir preconceitos ideológicos ou a projeção no passado de conceções peculiares da época moderna". ${ }^{29}$

É uma obra que provoca o intemporal, apesar de publicada há alguns anos, motivo suficiente desta Nota de Leitura.

Artigo recebido para publicação em: 13/12/2013

Artigo aprovado para publicação em: 26/02/2014

27 SIDJANSKI, op. cit., p. 109-110.

28 INDA, Jonathan; ROSALDO, Renato. Introduction. In: INDA, Jonathan; ROSALDO, Renato (Eds.), The Anthropology of Globalization. A Reader. MA-Oxford: Blackwell Publishers, 2002.

29 MATTOSO, José (dir.). História de Portugal, Vol. I - Antes de Portugal, op. cit., p. 15-16. 